\title{
MicroRNA-133b alleviates doxorubicin-induced cardiomyocyte apoptosis and cardiac fibrosis by targeting PTBP1 and TAGLN2
}

\author{
ZHEN LI ${ }^{1}$, ZEKANG YE ${ }^{2}$, JIAZHENG MA ${ }^{2}$, QIAN GU ${ }^{2}$, JIANZHEN TENG ${ }^{2}$ and XIAOXUAN GONG ${ }^{2}$ \\ Departments of ${ }^{1}$ Emergency and ${ }^{2}$ Cardiology, The First Affiliated Hospital of \\ Nanjing Medical University, Nanjing, Jiangsu 210029, P.R. China
}

Received December 3, 2020; Accepted March 4, 2021

DOI: $10.3892 /$ ijmm.2021.4958

\begin{abstract}
Doxorubicin is one of the most important chemotherapeutic drugs for the treatment of malignant tumors, but the cardiotoxicity of doxorubicin severely limits its clinical application. Increasing numbers of microRNAs (miRNAs/miRs) have been found to be dysregulated in doxorubicin-treated cardiomyocytes or animal hearts. The current study aimed to investigate the role of miR-133b in doxorubicin-induced cardiomyocyte injury. Doxorubicin was used to treat HL-1 cardiomyocytes to mimic cardiomyocyte injury in vitro. A mouse model of cardiac injury was generated by chronic intraperitoneal injections of doxorubicin. Masson's trichrome staining was performed on cardiac tissues to reveal cardiac fibrosis. Bioinformatics analysis and luciferase reporter assays were applied to explore the downstream targets of miR-133b. Flow cytometry and western blotting were conducted to detect cardiomyocyte apoptosis. Protein expression levels of collagen I, III and IV, and fibronectin were detected to reveal extracellular matrix deposition. The results revealed that doxorubicin decreased miR-133b expression in the treated HL-1 cardiomyocytes and mouse hearts. Overexpression of miR-133b restrained cardiomyocyte apoptosis, inhibited collagen accumulation and alleviated cardiac fibrosis in vivo. Mechanistically, polypyrimidine tract binding protein 1 (PTBP1) and transgelin 2 (TAGLN2) were confirmed to bind to miR-133b after prediction and screening. Moreover, miR-133b negatively regulated the protein expression levels of PTBP1 and TAGLN2. Finally, overexpression of PTBP1 or TAGLN2 reversed the effects of miR-133b on apoptosis and collagen accumulation. Thus, the current results indicated that miR-133b alleviated doxorubicin-induced cardiomyocyte apoptosis and cardiac fibrosis by targeting PTBP1
\end{abstract}

Correspondence to: $\mathrm{Dr}$ Xiaoxuan Gong, Department of Cardiology, The First Affiliated Hospital of Nanjing Medical University, 300 Guangzhou Road, Nanjing, Jiangsu 210029, P.R. China

E-mail: xiaoxuangong@sina.com

Key words: microRNA-133b, polypyrimidine tract binding protein 1 , transgelin 2 , doxorubicin, cardiomyocyte injury and TAGLN2, implying that miR-133b may be a potential biomarker for doxorubicin-induced cardiac injury.

\section{Introduction}

Doxorubicin, a broad-spectrum antitumor drug, has been reported to effectively treat various types of cancer, including hepatocellular carcinoma, lung cancer and gastric cancer (1-3). However, the accumulation of doxorubicin in the body may lead to cardiotoxicity, which results in cardiomyocyte apoptosis and collagen deposition, ultimately leading to dilated cardiomyopathy and heart failure (4-7). According to previous studies, a cumulative amount of $450-500 \mathrm{mg} / \mathrm{m}^{2}$ doxorubicin resulted in a $\sim 5 \%$ incidence of cardiotoxicity $(8,9)$. Furthermore, the incidence of cardiotoxicity was up to $18 \%$ at $550-660 \mathrm{mg} / \mathrm{m}^{2}$ doxorubicin $(8,9)$. The degree of coronary artery disease was a strong predictor for renal artery stenosis in multivariate analysis (10). However, the mechanism of doxorubicin-induced myocardial injury has not been fully elucidated.

MicroRNAs (miRNAs/miRs) are short, single-stranded, non-coding RNAs (11). Previous studies proposed that miRNAs can regulate $\sim 1 / 3$ of human genes and thereby exert their crucial biological functions in cellular behavior or tumorigenesis (11-13). Additionally, numerous miRNAs have been identified to be dysregulated in doxorubicin-treated cardiomyocytes or animal hearts, and these dysregulated miRNAs may influence several cellular processes, including oxidative damage and apoptosis $(14,15)$.

The miR-133 family consists of miR-133a-1, miR-133a-2 and miR-133b, and serves an important role in the pathophysiological processes of heart diseases $(16,17)$. miR-133b, located on chromosome 6 , has been reported to be dysregulated in human myocardial infarction and to regulate cardiac fibrosis $(18,19)$. Additionally, miR-133b has been widely reported to have antitumor potential (20-22) and to be closely associated with cardiotoxicity (23-25). miR-133b serves a cardioprotective role in morphine-preconditioned rat cardiomyocytes by inhibiting cardiomyocyte apoptosis (26) and can be used as a serum biomarker for cardiac fibrosis (27). Moreover, miR-133b expression is downregulated in doxorubicin-treated rat ventricular cardiomyocytes and rat cardiac tissues (28). The present study focused on the role of miR-133b in doxorubicin-induced myocardial injury. 
In the current study, HL-1 cardiomyocytes and C57BL/6 mice were treated with doxorubicin to establish a cell model and animal model of myocardial injury, respectively. The effects of miR-133b on fibrosis in cardiac tissues of doxorubicin-treated mice were investigated. Subsequently, the role of miR-133b in apoptosis and collagen deposition of doxorubicin-preconditioned cardiomyocytes was investigated, followed by exploration of the downstream targets of miR-133b.

\section{Materials and methods}

Ethics statement. All animal operations were in accordance with the guidelines on the use and care of laboratory animals for biomedical research (National Institutes of Health; no. 85-23; revised 1996). The experimental protocol was approved by the Ethics Committee of The First Affiliated Hospital of Nanjing Medical University (Nanjing, China; approval no. 2019-041).

Cell culture and treatment. Mouse HL-1 cardiomyocytes (The Cell Bank of Type Culture Collection of The Chinese Academy of Sciences) were cultured at $37^{\circ} \mathrm{C}$ in DMEM supplemented with $10 \%$ FBS (Gibco; Thermo Fisher Scientific, Inc.) in a humidified atmosphere containing $5 \% \mathrm{CO}_{2}$. For induction of apoptosis, different concentrations of doxorubicin (2.5, 5 and $10 \mu \mathrm{M}$; Teva UK Ltd.) were added to the medium for $6 \mathrm{~h}$ of culture at $37^{\circ} \mathrm{C}$. HL-1 cardiomyocytes in the control group (Con) were treated with the same dose of saline (Gibco; Thermo Fisher Scientific, Inc.).

Cell transfection. Full-length polypyrimidine tract binding protein 1 (PTBP1) or transgelin 2 (TAGLN2) was subcloned into pcDNA3.1 to overexpress PTBP1 or TAGLN2, respectively, and empty pcDNA3.1 was used as a control. Similarly, Bax was subcloned into pcDNA3.1 to overexpress Bax to detect if fibrotic events were independent of apoptosis. miR-133b mimics (miR-133b) and a negative control (miR-NC) were used to overexpress miR-133b. The sequence of the miR-133b mimics was 5'-UUUGGUCCCCUUCAACCAGCUA-3', and the sequence of the scrambled miR-NC was 5'-UCAUUGCUA UGCACUGUCCACC-3'. All pcDNA3.1 vectors $(1 \mu \mathrm{g})$ and miR-133b mimics (50 $\mathrm{nM})$ were purchased from Shanghai GenePharma Co., Ltd., and transfected in HL-1 cardiomyocytes using Lipofectamine ${ }^{\circledR} 3000$ (Invitrogen; Thermo Fisher Scientific, Inc.) at room temperature for $48 \mathrm{~h}$. After $48 \mathrm{~h}$ from transfection, subsequent experiments were conducted.

Flow cytometry assay. HL-1 cardiomyocyte apoptosis was tested using a PI/FITC Annexin V Apoptosis Detection kit (BD Pharmingen; BD Biosciences). Briefly, HL-1 cardiomyocytes $\left(5 \times 10^{5}\right.$ cells $\left./ \mathrm{ml}\right)$ were washed with cold PBS (Gibco; Thermo Fisher Scientific, Inc.) twice and then resuspended in $1 \mathrm{X}$ binding buffer. Subsequently, cell solution $\left(3 \times 10^{4}\right.$ cells; $100 \mu \mathrm{l}$ ) was added to a culture tube. Then, $5 \mu 1$ FITC Annexin V and $5 \mu \mathrm{l}$ of PI were added at room temperature in the dark for 15 min. Finally, HL-1 cardiomyocytes were analyzed using an Attune NxT flow cytometer (Invitrogen; Thermo Fisher Scientific, Inc.), and apoptotic cardiomyocytes were calculated using FlowJo software (version 10.0; FlowJo LLC). The apoptotic rate was calculated as follows: (Cell number in Q3/cell number in all quadrants) x100\%, with cells in Q3 representing early apoptotic cells.

Reverse transcription-quantitative PCR (RT-qPCR). Following the manufacturer's instructions, a miRNeasy Mini kit (Qiagen, Inc.) was used to extract RNA from HL-1 cardiomyocyte and mouse heart samples. The SScript $^{\mathrm{TM}}$ cDNA Synthesis kit (Bio-Rad Laboratories, Inc.) was used to reverse transcribe RNA (400 ng) to cDNA according to the manufacturer's protocol. The relative mRNA expression was determined using SYBR qPCR (Bio-Rad Laboratories, Inc.) with an ABI-7900 Real-Time PCR Detection System (7900HT; Applied Biosystems; Thermo Fisher Scientific, Inc.). The relative miR-133b expression was analyzed using Bulge-Loop ${ }^{\mathrm{TM}}$ miRNA qPCR Primer Set (Guangzhou RiboBio Co., Ltd.) with an ABI-7900 Real-Time PCR Detection System. qPCR was performed with the following thermocycling conditions: $95^{\circ} \mathrm{C}$ for $30 \mathrm{sec}$, followed by 40 cycles at $95^{\circ} \mathrm{C}$ for $5 \mathrm{sec}$ and $60^{\circ} \mathrm{C}$ for $30 \mathrm{sec}$, and a melting curve analysis protocol $\left(60-95^{\circ} \mathrm{C}\right.$ with temperature increments of $0.2^{\circ} \mathrm{C}$ every $\left.10 \mathrm{sec}\right) . \mathrm{GAPDH}$ and U6 were used as internal controls for mRNA and miRNA, respectively. The relative gene expression level was calculated using the $2^{-\Delta \Delta \mathrm{Cq}}$ method (29). The primer sequences were as follows: PTBP1 forward, 5'-GATCCGACGAGCTCTTCTC-3' and reverse, 5'-CTATCGTTTCCATTGGCTGC-3'; TAGLN2 forward, 5'-CCAACTGGTTTCCTAAGAAATCC-3' and reverse, 5'-CAATCACGTTCTTGCCCTC-3'; LHFP forward, 5'-TTTGACTTGGGCAAGTGTG-3' and reverse, 5'-CAT GTACACAGCAGCATGG-3'; SEC61B forward, 5'-TTGCTC TTCCCAGCTTCTC-3' and reverse, 5'-TGTAGAATCGCC ACATCCC-3'; CETN3 forward, 5'-TTAGCTCTGAGAGGT GAGC-3' and reverse, 5'-TTCTTGCTTCTGTTCTTCAGA G-3'; FTL forward, 5'-CCGTGCACTCTTCCAGGATGT-3' and reverse, 5'-CCTTATCCAGATAGTGGCTTTCCAG-3'; LDLRAP1 forward, 5'-TGACACTCAAGGTGTCACC-3' and reverse, 5'-TAGGAGATCCTGTAAATGGACAC-3'; CLTA forward, 5'-ATACTACCAGGAGAGCAATGG-3' and reverse, 5'-TACTTTCAGGCTCTGACTGC-3'; GAPDH forward, 5'-CATCTTCTTGTGCAGTGCC-3' and reverse, 5'-CAAATC CGTTCACACCGAC-3'; miR-133b forward, 5'-TTGGTCCCC TTCAACCAGCTA-3' and reverse, 5'-CAGTGCGTGTCG TGGAGT-3'; and U6 forward, 5'-CTCGCTTCGGCAGCA CA-3' and reverse, 5'-ACGCTTCACGAATTTGCGT-3'.

Western blotting. HL-1 cardiomyocytes and mouse cardiac tissues were lysed using RIPA lysis buffer (Beyotime Institute of Biotechnology). A Bicinchoninic Acid Protein Assay kit (Thermo Fisher Scientific, Inc.) was used to evaluate the concentration of protein samples $(1 \mu \mathrm{l})$. Subsequently, equal amounts of protein samples ( $50 \mu \mathrm{g} /$ lane) were subjected to $12 \%$ SDS-PAGE and transferred to PVDF membranes, which were then blocked with $5 \%$ skimmed milk at $4^{\circ} \mathrm{C}$ overnight. Primary antibodies (1:1,000) against cleaved caspase-3 (cat. no. ab2302), Bcl-2 (cat. no. ab32124), Bax (cat. no. ab32503), collagen I (cat. no. ab34710), collagen III (cat. no. ab7778), fibronectin (cat. no. ab2413), collagen IV (cat. no. ab214417), PTBP1 (cat. no. ab133734), TAGLN2 (cat. no. ab121146) and GAPDH (cat. no. ab181602) were then incubated with the membranes at $4^{\circ} \mathrm{C}$ overnight. Collagen I, III and IV, and fibronectin are extracellular matrix (ECM) proteins. Finally, HRP-conjugated 
secondary antibodies (cat. no. ab6721; 1:5,000) were added to the membranes in the dark at room temperature for $1 \mathrm{~h}$. All antibodies were obtained from Abcam. Proteins were visualized using an ECL Chemiluminescence kit (Thermo Fisher Scientific, Inc.) and quantified using ImageJ software (version 1.46; National Institutes of Health). GAPDH served as a loading control. The gray ratio of the target bands to the internal reference bands was the relative expression of the target proteins.

RNA immunoprecipitation (RIP) assay. The RIP assay was performed using a Magna RIP ${ }^{\mathrm{TM}}$ RNA-Binding Protein Immunoprecipitation kit (EMD Millipore) according to the manufacturer's protocol. After centrifugation at $1,000 \mathrm{x} \mathrm{g}$ at $4^{\circ} \mathrm{C}$ for $5 \mathrm{~min}$, HL-1 cardiomyocytes were lysed in complete RIPA lysis buffer (cat. no. P0013B; Beyotime Institute of Biotechnology). Subsequently, $100 \mu 1$ supernatant was collected and incubated with magnetic beads ( $1 \mathrm{mg}$ ) conjugated with PTBP1 antibody (cat. no. ab133734; 1:10,000; Abcam) or control IgG (cat. no. 12-370; 1:5,000; EMD Millipore) at $4^{\circ} \mathrm{C}$ for $6 \mathrm{~h}$. After the beads were washed, the complexes were treated with Proteinase $\mathrm{K}$ to remove proteins. Beads were isolated from the supernatant after centrifugation at $2,500 \mathrm{x} \mathrm{g}$ for $5 \mathrm{~min}$ at $4^{\circ} \mathrm{C}$ and washed with washing buffer $(10 \mathrm{mM}$ Tris- $\mathrm{HCl} \mathrm{pH} 7.5,1 \mathrm{mM}$ EDTA, $2 \mathrm{M} \mathrm{NaCl}$ and $0.1 \%$ Tween-20), followed by another centrifugation step at 2,500 $\mathrm{x}$ g for $5 \mathrm{~min}$ at $4^{\circ} \mathrm{C}$. Finally, the purified RNA level was measured by RT-qPCR, as aforementioned.

Bioinformatics analysis. Based on the TargetScan version 7.2 website (http://www.targetscan.org/vert_72/), 703 mRNAs were predicted to harbor binding site(s) for miR-133b (data not shown). According to the starBase v2.0 website (http://starbase. sysu.edu.cn/), PTBP1 was predicted to bind to the 3'-untranslated region (UTR) of TAGLN2 (data not shown). According to the RNA-Protein Interaction Prediction (http://pridb.gdcb. iastate.edu) based on the random forest (RF) and support vector machine (SVM) algorithm, scores of the combination between PTBP1 and TAGLN2 3'-UTR, and between PTBP1 and TAGLN2 were evaluated.

Luciferase reporter assay. A fragment of the PTBP1 or TAGLN2 3'-UTR containing the predicted binding site of miR-133b was cloned into the pmirGLO vector (Promega Corporation) to construct the wild-type pmirGLO-PTBP1-3'-UTR or pmirGLO-TAGLN2-3'-UTR vectors. The mutant pmirGLO-PTBP1-3'-UTR or pmirGLO-TAGLN2-3'-UTR vectors were also generated by subcloning the mutated PTBP1 or TAGLN2 sequences in the 3'-UTR complementary to $\mathrm{miR}-133 \mathrm{~b}$ into the pmirGLO vectors. The vectors were commercially obtained from Shanghai GenePharma Co., Ltd., and then separately transfected with miR-NC or miR-133b mimics using Lipofectamine 3000, as aforementioned. The luciferase activity was evaluated using a dual luciferase reporter assay system (Promega Corporation) $48 \mathrm{~h}$ after transfection, and was normalized to Renilla luciferase activity.

RNA pulldown assay. A total of $6 \times 10^{6}$ cells were cultured in a $100-\mathrm{mm}$ culture dish. After discarding the culture medium, cells were washed twice with PBS. Next, cells were digested using $0.5 \mathrm{ml}$ trypsin followed by addition of $2 \mathrm{ml}$ PBS. Cells were transferred to EP tubes followed by centrifugation at $1,000 \mathrm{x} \mathrm{g}$ at $4^{\circ} \mathrm{C}$ for $2 \mathrm{~min}$ and were subsequently treated with $100 \mu \mathrm{l}$ buffer solution for $15 \mathrm{~min}$. After another centrifugation at $1,000 \mathrm{x} \mathrm{g}$ at $4^{\circ} \mathrm{C}$ for $5 \mathrm{~min}$, the supernatant was collected. The TAGLN2 sense or antisense sequence was transcribed using T7 RNA polymerase (cat. no. AM2718; Ambion; Thermo Fisher Scientific) and then purified using the RNeasy Plus Mini kit (cat. no. 74134; Qiagen GmbH) according to the manufacturer's protocol. Subsequently, the TAGLN2 sense or antisense sequence was labeled with Biotin RNA Labeling Mix (Ambio Life). Subsequently, a Magnetic RNA-Protein Pull-Down kit (cat. no. 20164; Pierce; Thermo Fisher Scientific, Inc.) was used for RNA pulldown assays according to the manufacturer's instructions. Beads were isolated from the supernatant after boiling, and the PTBP1 enrichment was analyzed by western blotting.

Mouse model and adeno-associated virus (AAV) injection. A total of 50 C57BL/6 mice (20-25 g; 8 weeks old; male; Beijing Vital River Laboratory Animal Technology Co., Ltd.) were used in the present study and were grouped as follows: Sham group $(n=15)$, DOX+AAV-NC group $(n=15)$ and DOX+AAV-miR-133b group $(n=20)$. Mice were raised with ad libitum access to water and food in a temperature-controlled room $\left(22 \pm 2^{\circ} \mathrm{C}\right)$ with a 12-h light/dark cycle and a relative humidity of $40-60 \%$. A cardiac injury mouse model was generated by chronic intraperitoneal injections (on days $0,2,4$ and 6) of $4 \mathrm{mg} / \mathrm{kg}$ doxorubicin. The mice in the sham group were treated with the same dose of PBS (Invitrogen; Thermo Fisher Scientific, Inc.). All mice were euthanized 4 weeks after the first injection of doxorubicin or PBS. For AAV (serotype 9) injection, mice received a single-bolus injection of AAV-miR-133b or empty AAV (AAV-NC) resuspended in PBS via the tail vein at $1 \times 10^{11}$ viral genomes per animal. AAV vectors were purchased from Han Heng Biotechnology (Shanghai) Co., Ltd. One week after injection of AAVs, the mice were treated with doxorubicin or PBS. The mice were anesthetized with $1.5 \%$ pentobarbital sodium $(60 \mathrm{mg} / \mathrm{kg})$ by intraperitoneal injection and then sacrificed by cervical dislocation under anesthesia. The whole experiment lasted 5 weeks, beginning from AAV injection and ending up with the euthanasia of mice.

Echocardiography. Four weeks after the first injection of doxorubicin or PBS, the mice were anesthetized with $2 \%$ isoflurane and placed in the supine position. The left ventricular end-systolic diameter (LVESD) and left ventricular end-diastolic diameter (LVEDD) values were analyzed using a VEVO 770 high-resolution system (VisualSonics, Inc.) with a RMV 704 probe at a frequency of $40 \mathrm{MHz}$. Left ventricular ejection fraction (LVEF) and left ventricular ejection shorting (LVES) were automatically calculated using an echocardiographic instrument.

Masson's trichrome staining. Cardiac tissue samples were immobilized in $4 \%$ paraformaldehyde for $48 \mathrm{~h}$ at $4^{\circ} \mathrm{C}$, embedded in paraffin and sliced into sections (5- $\mu$ m-thick). Subsequently, sections were subjected to Masson's trichrome staining as previously described (30). The collagen fibers were blue, the muscles and elastic fibers were red, cellulose 
A

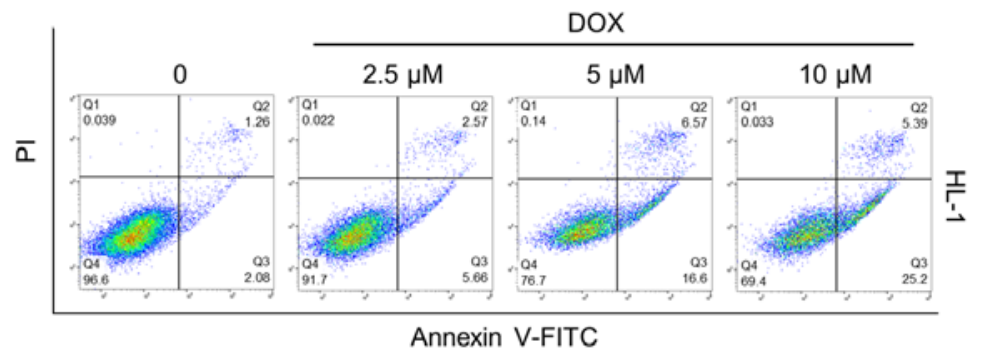

Annexin V-FITC

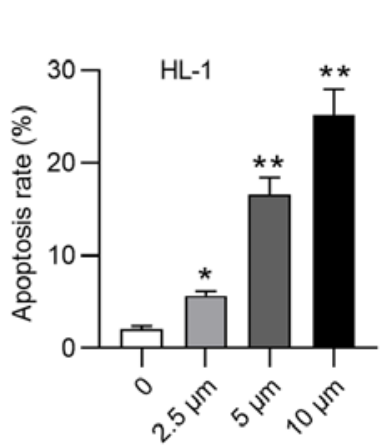

B

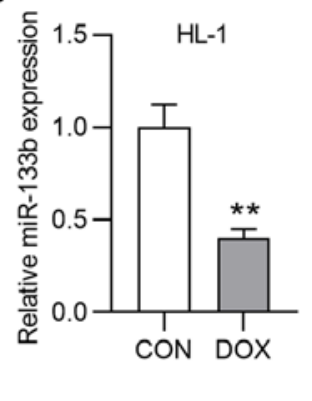

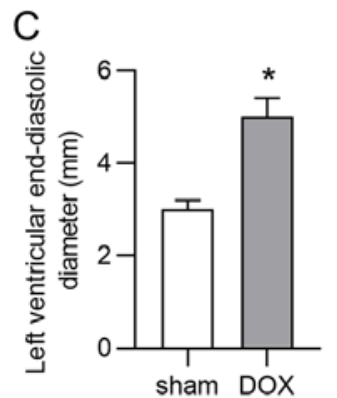
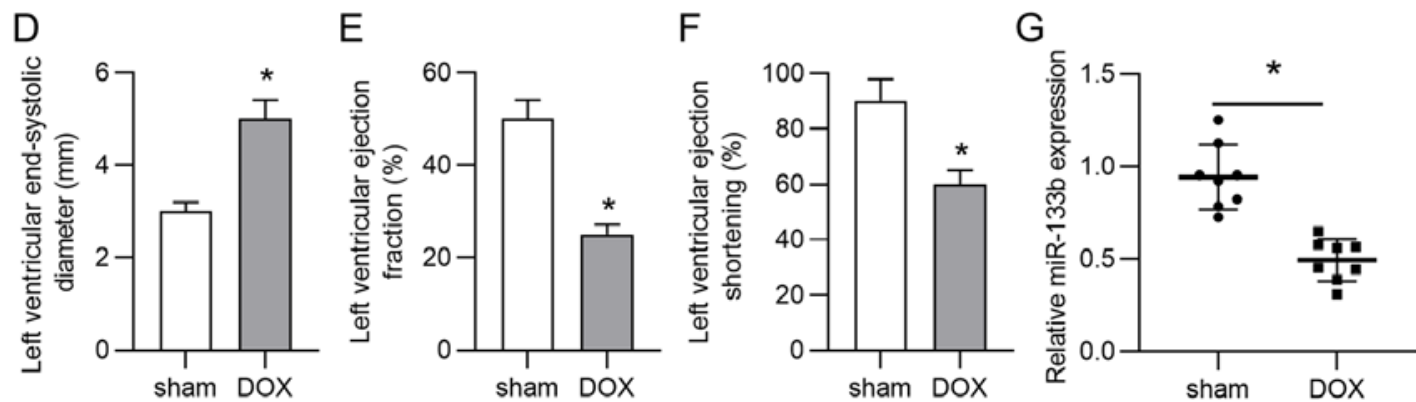

Figure 1. miR-133b expression is decreased by doxorubicin treatment in HL-1 cardiomyocytes and cardiac tissues. (A) Apoptosis of HL-1 cardiomyocytes induced by different concentrations of doxorubicin was determined by flow cytometry. ${ }^{*} \mathrm{P}<0.05$ and ${ }^{* *} \mathrm{P}<0.01$ vs. $0 \mu \mathrm{m}$. (B) RT-qPCR assays were used to measure miR-133b expression in the HL-1 cardiomyocytes treated with or without doxorubicin. ${ }^{* *} \mathrm{P}<0.01 \mathrm{vs}$. CON. Echocardiography analysis was adopted to examine (C) left ventricular end-diastolic diameter, (D) left ventricular end-systolic diameter, (E) left ventricular ejection fraction and (F) left ventricular ejection shortening in mice ( $\mathrm{n}=8 /$ group). (G) RT-qPCR assays were used to measure miR-133b expression in the sham and DOX groups ( $\mathrm{n}=8 / \mathrm{group}$ ). "P<0.05 vs. sham. miR, microRNA; DOX, doxorubicin; CON, control; RT-qPCR, reverse transcription-quantitative PCR.

was purple-red, and the nucleus was blue-brown. Images were taken using a light microscope Nikon model with a Spot Insight camera (magnification, $\mathrm{x} 200$ ). The fibrotic region was quantified using ImageJ software (version 1.46; National Institutes of Health). The percentage of fibrosis was calculated as fibrosis areas/total left ventricular areas $\mathrm{x} 100 \%$.

Measurement of collagen content. The collagen content was determined using a quantitative dye-binding method, as previously described (30). A Sircol assay (Biocolor Ltd.) was used to analyze cardiac tissues following the manufacturer's instructions. The mouse heart was weighed and homogenized with pepsin, and collagen content in each sample was quantified using the Gen5 ${ }^{\mathrm{TM}}$ BioTek software (Agilent Technologies, Inc.).

Statistical analysis. The data are displayed as the mean \pm SD of 3 independent experiments. Statistical analysis was performed using SPSS software (version 21.0; IBM Corp.). All data were assessed for normal distribution (Shapiro-Wilk test) and homogeneity of variance (Bartlett's test). Statistical analysis was performed using unpaired Student's t-test for comparisons between two groups or one-way ANOVA followed by Dunnett's or Tukey's post-hoc tests for comparisons among multiple groups. $\mathrm{P}<0.05$ was considered to indicate a statistically significant difference.

\section{Results}

miR-133b expression is decreased by doxorubicin treatment in $H L-1$ cardiomyocytes and cardiac tissues. As shown in Fig. 1A, the apoptosis rate of HL-1 cardiomyocytes was significantly increased by treatment with doxorubicin $(2.5,5$ and $10 \mu \mathrm{M})$. Considering that $10 \mu \mathrm{M}$ doxorubicin resulted in the highest apoptosis rate of HL-1 cardiomyocytes, $10 \mu \mathrm{M}$ doxorubicin was selected for subsequent assays. However, the role of miR-133b in doxorubicin-induced cardiac injury remains unclear. According to the RT-qPCR results, doxorubicin treatment significantly decreased miR-133b expression in HL-1 cells (Fig. 1B). A mouse model of cardiac injury was then established by injection of doxorubicin. Data from echocardiography analysis demonstrated that the LVEDD and LVESD were significantly increased by doxorubicin injection (Fig. 1C and D), while LVEF and LVES were significantly decreased by doxorubicin injection (Fig. 1E and F). Additionally, miR-133b expression was significantly downregulated in the DOX group compared with in the sham group (Fig. 1G). All these experimental results suggested that miR-133b expression was decreased by doxorubicin treatment in vitro and in vivo.

Overexpression of miR-133b inhibits the apoptosis and collagen accumulation in doxorubicin-treated $H L-1$ cardiomyocytes. The biological function of miR-133b in doxorubicin-treated HL-1 cardiomyocytes was then explored. First, miR-133b was overexpressed by transfection using miR-133b mimics in doxorubicin-treated HL-1 cardiomyocytes (Fig. 2A). miR-133b overexpression significantly decreased the apoptosis rate of doxorubicin-treated HL-1 cardiomyocytes (Fig. 2B). Moreover, western blot assays revealed that miR-133b overexpression triggered a significant increase in $\mathrm{Bcl}-2$ protein expression, but a significant decrease in Bax and cleaved caspase- 3 protein expression (Fig. 2C and D). As shown in Fig. 2E and F, overexpression 
A

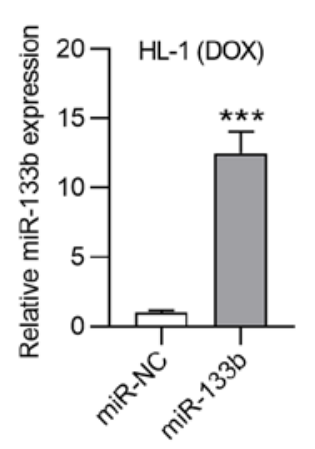

D

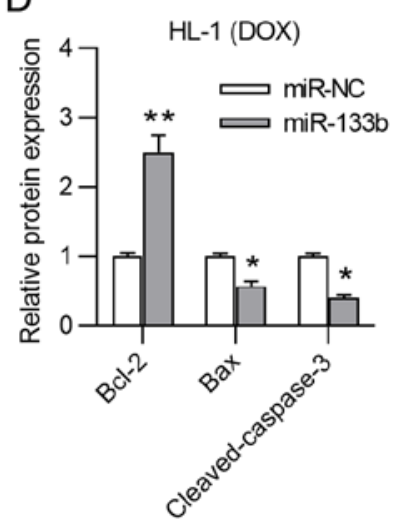

B

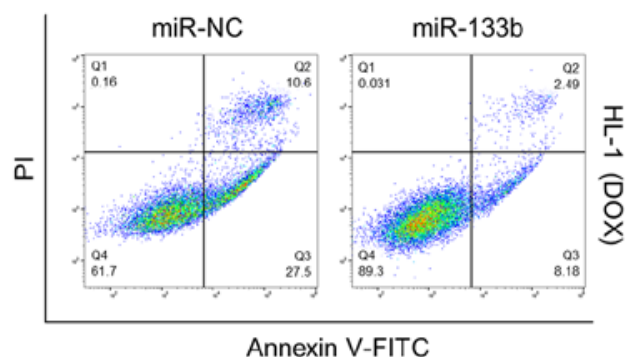

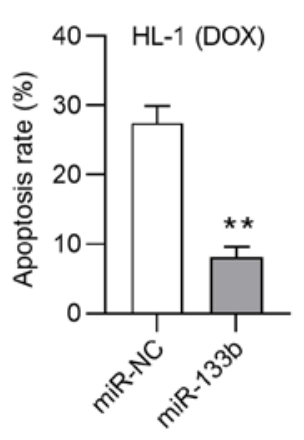

C

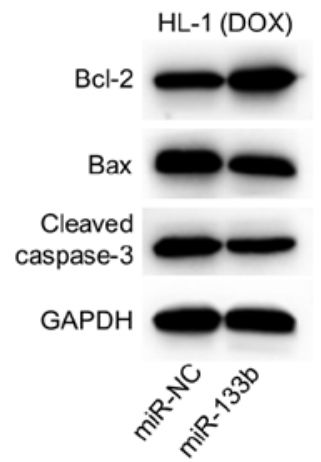

E

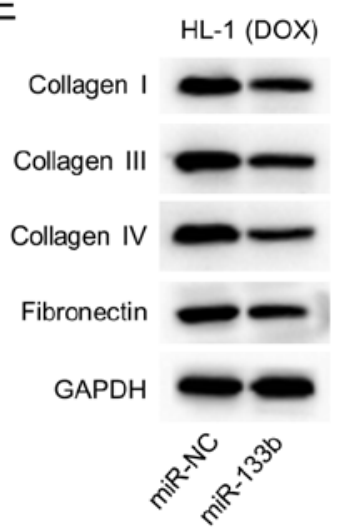

F

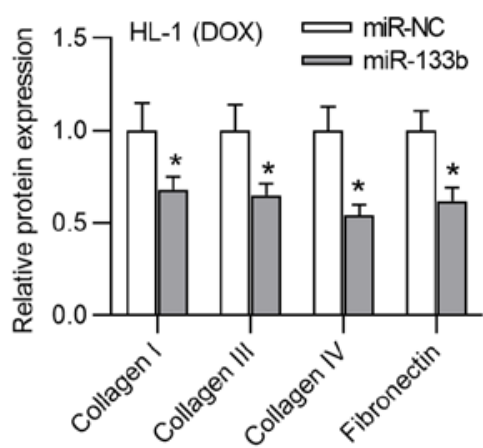

Figure 2. Overexpression of miR-133b inhibits the apoptosis and collagen accumulation in the doxorubicin-treated HL-1 cardiomyocytes. (A) Overexpression efficiency of miR-133b mimics was evaluated by reverse transcription-quantitative PCR in the doxorubicin-treated HL-1 cardiomyocytes. (B) Effect of miR-133b overexpression on apoptosis of the doxorubicin-treated HL-1 cardiomyocytes was assessed by flow cytometry. Western blot assays of the changes in the protein expression levels of (C and D) Bcl-2, Bax and cleaved caspase-3, and (E and F) collagen I, III and IV, and fibronectin in the doxorubicin-treated HL-1 cardiomyocytes transfected with miR-NC or miR-133b mimics. ${ }^{*} \mathrm{P}<0.05,{ }^{* *} \mathrm{P}<0.01$ and ${ }^{* * *} \mathrm{P}<0.001$ vs. miR-NC. miR, microRNA; DOX, doxorubicin; NC, negative control.

of miR-133b significantly decreased the protein expression levels of collagen I, III and IV, and fibronectin in the doxorubicin-treated HL-1 cardiomyocytes. Moreover, it was revealed that BAX was successfully overexpressed and that BAX overexpression had no significant effects on the expression levels of ECM proteins (Fig. S1A and B). Overall, miR-133b overexpression inhibited the apoptosis and collagen accumulation in the doxorubicin-treated HL-1 cardiomyocytes.

Overexpression of $m i R-133 b$ alleviates apoptosis and cardiac fibrosis in vivo. To explore the role of miR-133b in vivo, a mouse model of doxorubicin-induced heart failure was established. First, it was observed that miR-133b expression in the AAV-miR-NC group was significantly decreased compared with in the sham group, and miR-133b expression was significantly increased in cardiac tissues by AAV-miR-133b injection (Fig. 3A). In addition, the injection of doxorubicin induced a significant decrease in Bcl-2 protein expression, but a significant increase in Bax and cleaved caspase- 3 protein expression, and miR-133b overexpression reversed these effects (Fig. 3B). Furthermore, Masson's trichrome staining indicated that miR-133b overexpression significantly attenuated doxorubicin-induced cardiac fibrosis and collagen deposition (Fig. 3C-F). Similarly, western blot assays suggested that the doxorubicin-induced augmentation of the protein expression levels of collagen I, III and IV, and fibronectin were also antagonized by miR-133b overexpression (Fig. 3G). In conclusion, overexpression of miR-133b alleviated apoptosis and cardiac fibrosis in vivo.

PTBP1 and TAGLN2 are targets of miR-133b. Previously, miR-133b has been widely reported to bind to the 3'-UTR of mRNAs to exert its biological functions $(26,31)$. Hence, it was hypothesized that miR-133b functioned in the same way in HL-1 cardiomyocytes. According to the TargetScan website, $703 \mathrm{mRNAs}$ were predicted to harbor binding site(s) for miR-133b (data not shown). The top 8 mRNAs (LHFP, SEC61B, CETN3, PTBP1, FTL, LDLRAP1, CLTA and TAGLN2) with the highest total context score were chosen for subsequent experiments. According to RT-qPCR, PTBP1 and TAGLN2 expression was significantly upregulated in the doxorubicin-treated HL-1 cardiomyocytes compared with in control cells, suggesting that PTBP1 and TAGLN2 may be target mRNAs of miR-133b (Fig. 4A). Subsequently, the binding site between miR-133b and PTBP1 or TAGLN2 was predicted using the TargetScan website (Fig. 4B). Luciferase reporter assays demonstrated that the luciferase activity of wild-type pmirGLO-PTBP1-3'-UTR or pmirGLO-TAGLN2-3'-UTR was significantly inhibited by miR-133b mimics, while the mutant pmirGLO-PTBP1-3'-UTR or pmirGLO-TAGLN2-3'-UTR displayed no changes (Fig. 4C). Additionally, the expression levels of PTBP1 and TAGLN2 were significantly upregulated in the DOX group compared with in the sham group (Fig. 4D). In addition, miR-133b overexpression significantly decreased 
A

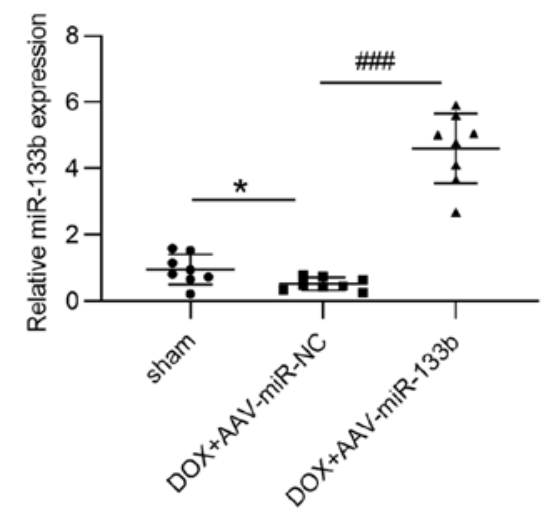

C

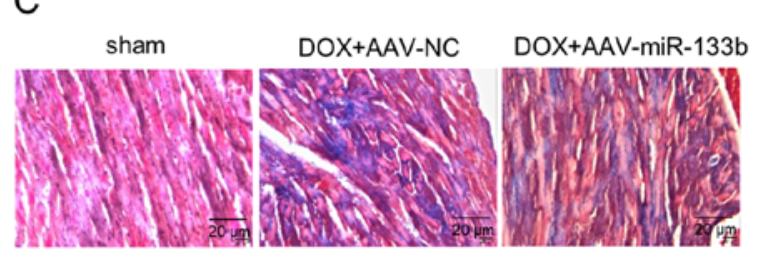

B

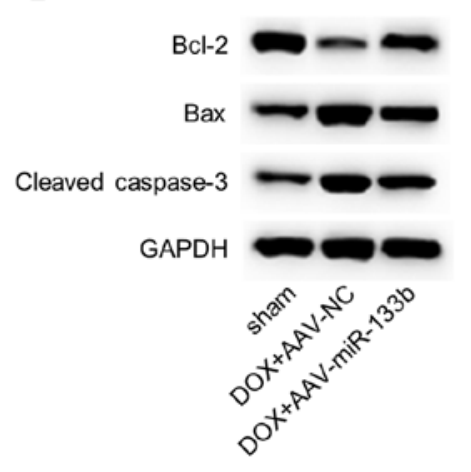

D

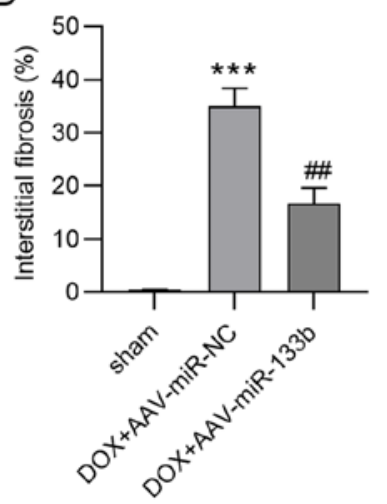

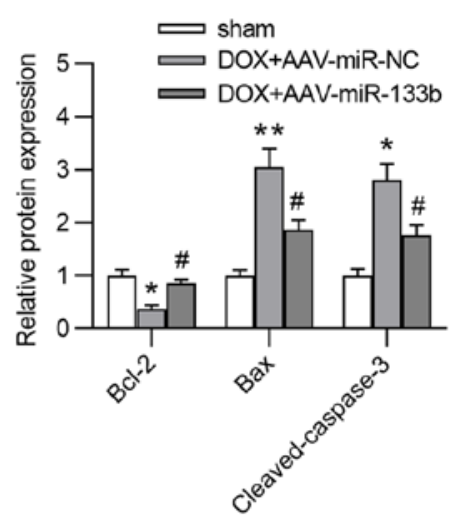

E

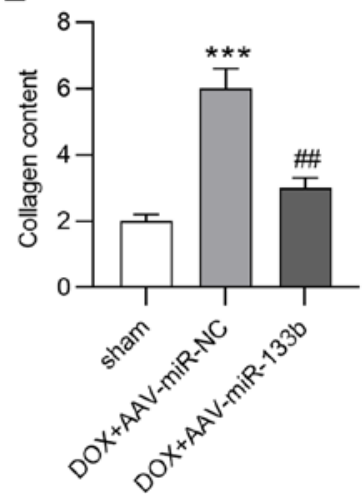

F
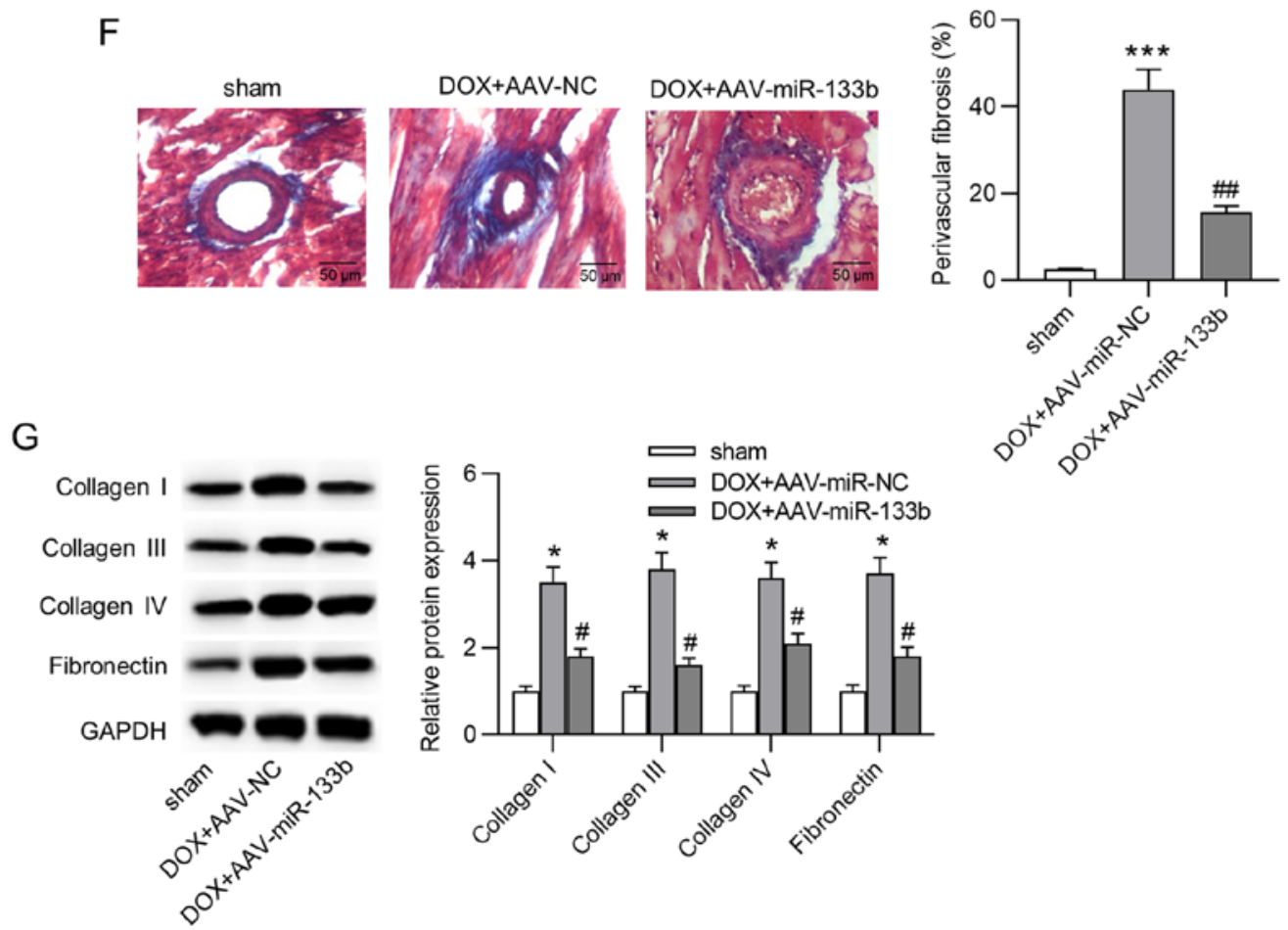

Figure 3. Overexpression of miR-133b alleviates apoptosis and cardiac fibrosis in vivo. (A) Overexpression efficacy of AAV-miR-133b was confirmed by reverse transcription-quantitative PCR ( $\mathrm{n}=8$ /group). (B) Protein expression levels of Bcl-2, Bax and cleaved caspase-3 in cardiac tissues were determined by western blot assays ( $n=8 /$ group). (C and D) Masson's trichrome staining was used to evaluate interstitial fibrosis in the mouse heart ( $\mathrm{n}=8 /$ group). Scale bar, $20 \mu \mathrm{m}$. (E) Collagen content in cardiac tissues ( $\mathrm{n}=8 /$ group). (F) Masson's staining of myocardial peripheral vessels and the percentage of perivascular fibrosis ( $\mathrm{n}=8$ /group). Scale bar, $50 \mu \mathrm{m}$. (G) Protein expression levels of collagen I, III and IV, and fibronectin in cardiac tissues were determined by western blot assays (n=8/group). ${ }^{*} \mathrm{P}<0.05,{ }^{* *} \mathrm{P}<0.01$ and ${ }^{* * *} \mathrm{P}<0.001$ vs. sham; ${ }^{\#} \mathrm{P}<0.05,{ }^{\# \#} \mathrm{P}<0.01$ and ${ }^{\# \#} \mathrm{P}<0.001$ vs. DOX+AAV-miR-NC. miR, microRNA; DOX, doxorubicin; NC, negative control; AAV, adeno-associated virus.

TAGLN2 and PTBP1 protein expression in HL-1 cardiomyocytes (Fig. 4E). Coincidently, according to the starBase website,
PTBP1 was predicted to bind to the 3'-UTR of TAGLN2 (data not shown). The interaction between the PTBP1 protein and the 
A

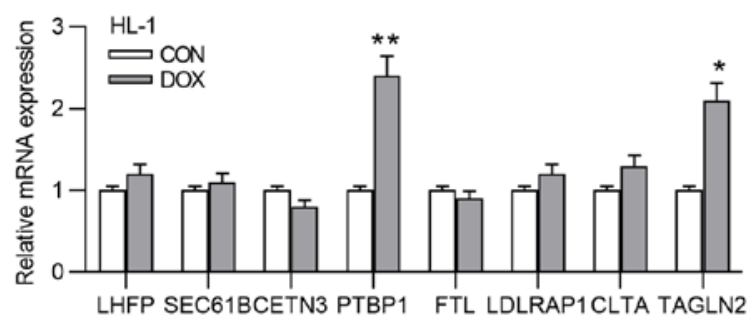

B

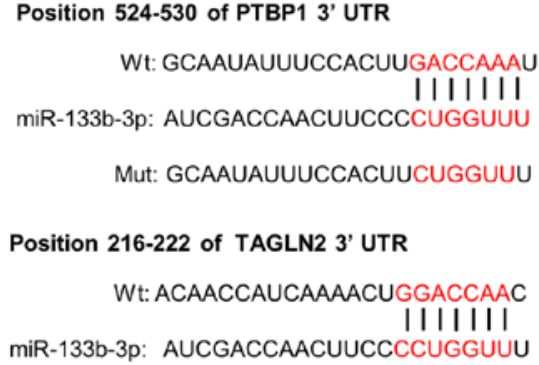

Mut: ACAACCAUCAAAACUCCUGGUUC
C

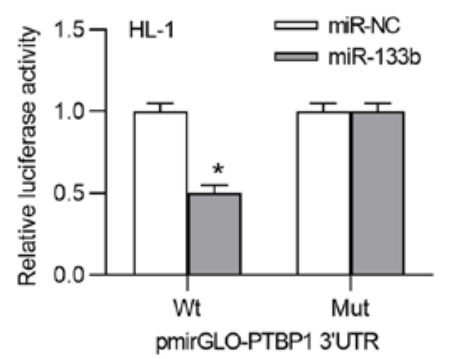

E

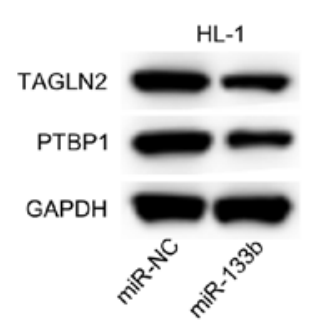

G

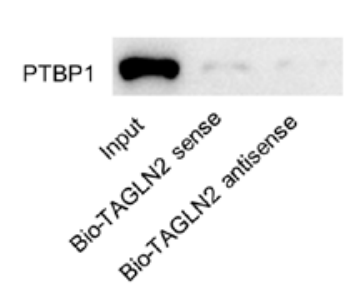

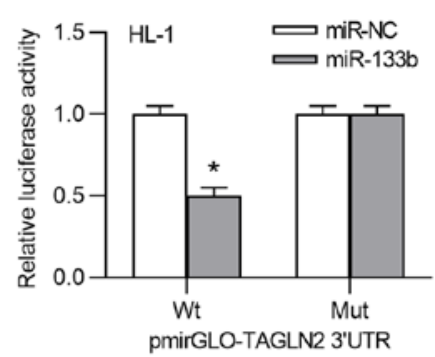

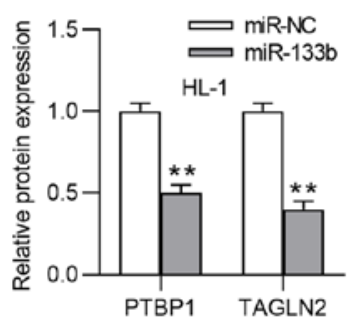

$\mathrm{H}$

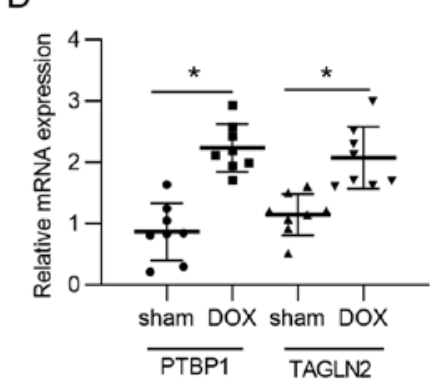

F

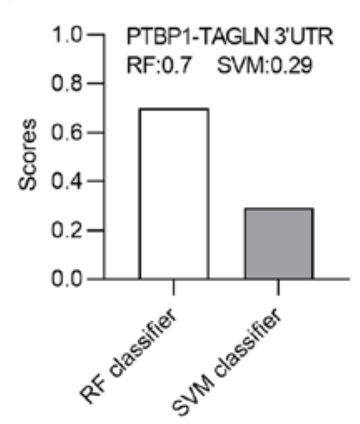

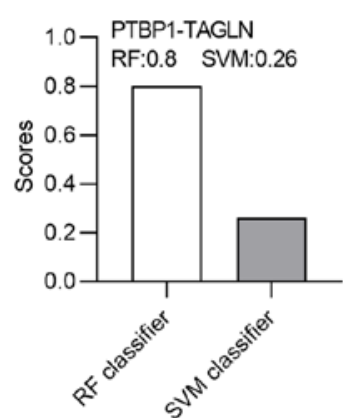

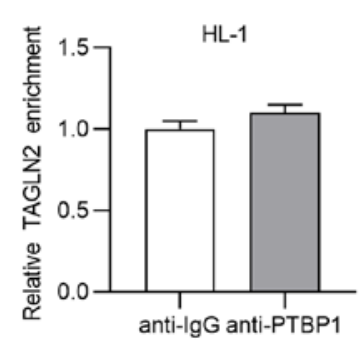

Figure 4. PTBP1 and TAGLN2 serve as targets of miR-133b. (A) mRNA expression levels of predicted mRNAs in HL-1 cardiomyocytes treated with or without doxorubicin. ${ }^{*} \mathrm{P}<0.05$ and ${ }^{* *} \mathrm{P}<0.01$ vs. CON. (B) Binding sites between miR-133b and PTBP1 or TAGLN2. (C) Luciferase reporter assay was adopted to confirm the interaction between miR-133b and PTBP1 or TAGLN2. * $<0.05$ vs. miR-NC. (D) mRNA expression levels of PTBP1 and TAGLN2 in the sham and DOX groups. "P<0.05. (E) Western blot assays of the changes in the PTBP1 and TAGLN2 protein expression levels in the doxorubicin-treated HL-1 cardiomyocytes transfected with miR-NC or miR-133b mimics. ${ }^{* *} \mathrm{P}<0.01$ vs. miR-NC. (F) RF classifier score and SVM classifier score of the combination of PTBP1 and the TAGLN2 3'-UTR or TAGLN2. (G) RNA pulldown and (H) RNA immunoprecipitation assays were utilized to evaluate the interaction between PTBP1 and TAGLN2. miR, microRNA; DOX, doxorubicin; CON, control; NC, negative control; UTR, untranslated region; PTBP1, polypyrimidine tract binding protein 1; TAGLN2, transgelin 2; Wt, wild-type; Mut, mutant; Bio, biotin; RF, random forest; SVM, support vector machine.

TAGLN2 3'-UTR was then evaluated. Data from RNA-Protein Interaction Prediction revealed that the RF classifier score and SVM classifier score of the combination between PTBP1 and TAGLN2 3'-UTR were 0.7 and 0.29, respectively, while the scores of the combination between PTBP1 and TAGLN2 were 0.8 and 0.26 , respectively (Fig. 4F). Subsequently, an RNA pulldown assay indicated that PTBP1 was enriched only in the input group (Fig. 4G), and a RIP assay demonstrated that neither anti-IgG nor anti-PTBP1 immunoprecipitated TAGLN2 (Fig. 4H), indicating that PTBP1 was unable to bind to the TAGLN2 3'-UTR. Thus, PTBP1 and TAGLN2 served as targets of miR-133b.

Overexpression of PTBP1 or TAGLN2 reverses the effects of miR-133b on apoptosis and collagen accumulation. To validate whether miR-133b modulated apoptosis and collagen deposition by targeting PTBP1 and TAGLN2 in the doxorubicin-treated HL-1 cardiomyocytes, rescue assays were performed via PTBP1 and TAGLN2 overexpression. PTBP1 and TAGLN2 overexpression efficiency was verified by RT-qPCR (Fig. S1C and D). 
A

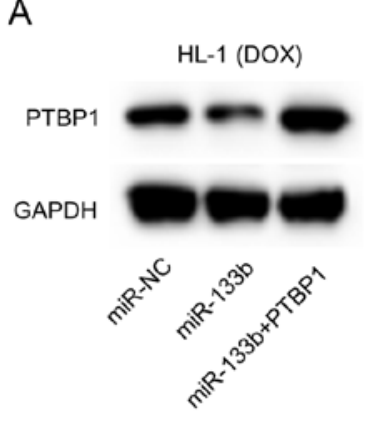

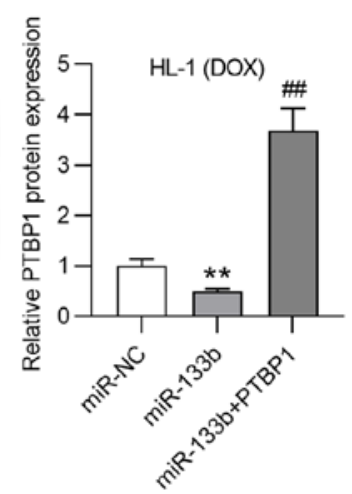

B

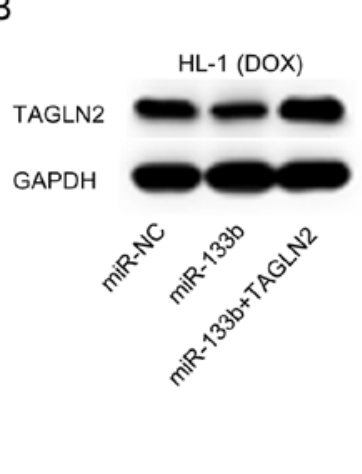

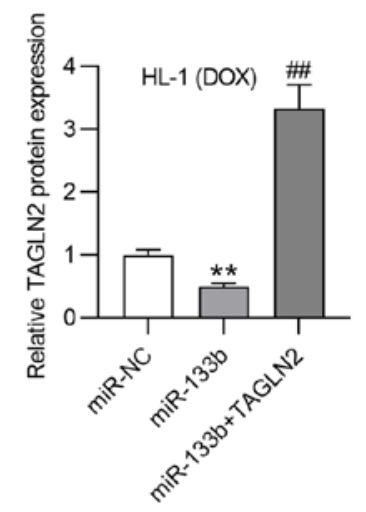

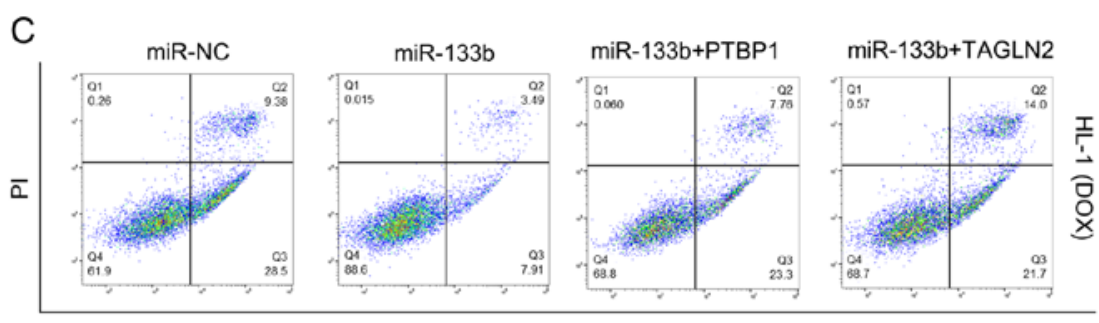

Annexin V-FITC
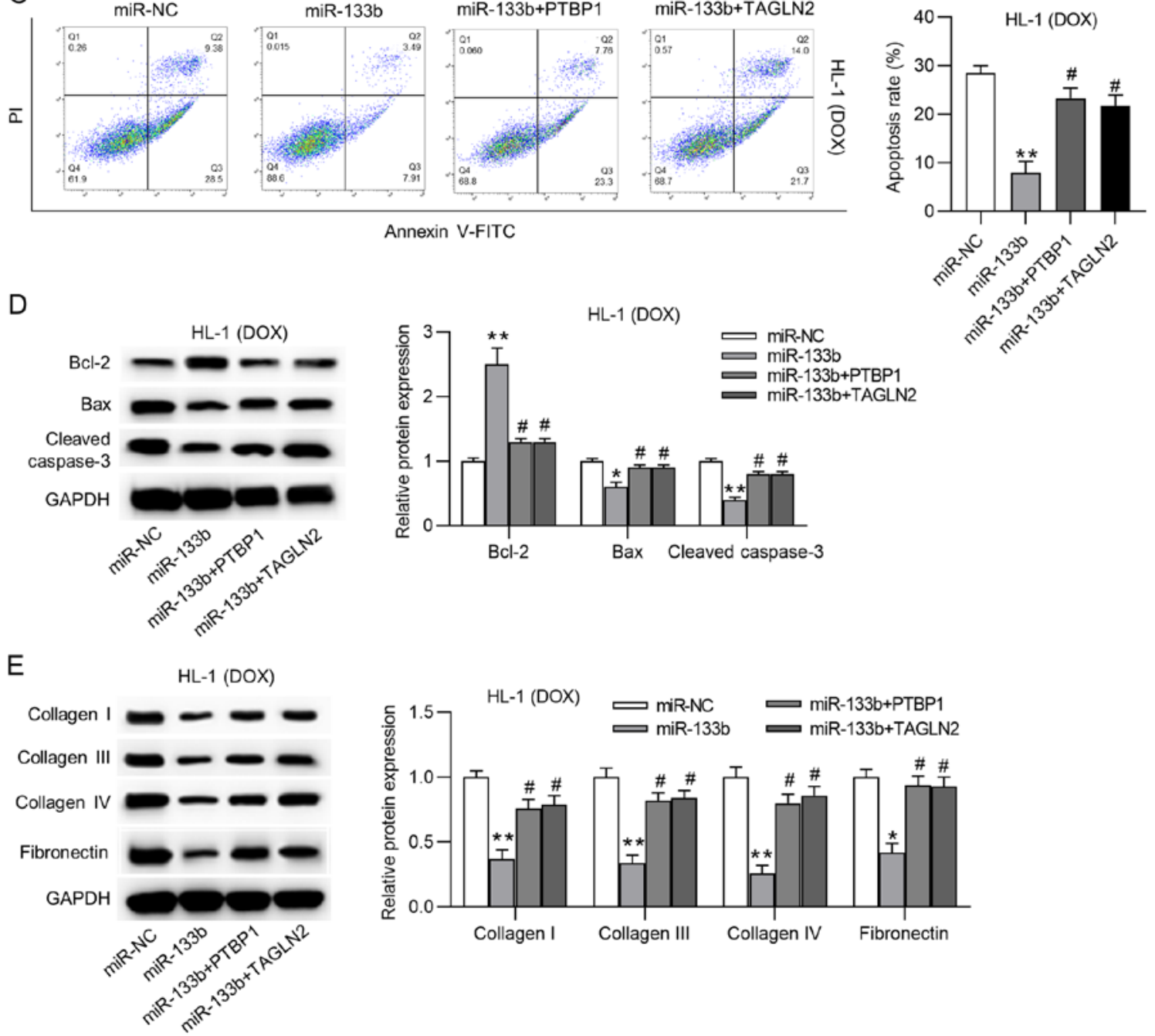

Figure 5. Overexpression of PTBP1 or TAGLN2 reverses the effects of miR-133b on apoptosis and collagen accumulation. Overexpression of (A) PTBP1 or (B) TAGLN2 in the doxorubicin-treated HL-1 cardiomyocytes following miR-133b overexpression was assessed by reverse transcription-quantitative PCR assays. (C) Flow cytometry was used to examine the apoptosis in the indicated groups. Western blot assays were performed to explore the protein expression levels of (D) Bcl-2, Bax and cleaved caspase-3, and (E) collagen I, III and IV, and fibronectin in the indicated groups. " $\mathrm{P}<0.05$ and ${ }^{* *} \mathrm{P}<0.01 \mathrm{vs.} \mathrm{miR-NC;}{ }^{*} \mathrm{P}<0.05$ and ${ }^{\# \#} \mathrm{P}<0.01$ vs. miR-133b. miR, microRNA; DOX, doxorubicin; NC, negative control; PTBP1, polypyrimidine tract binding protein 1; TAGLN2, transgelin 2.

The protein expression levels of PTBP1 and TAGLN2 were significantly increased by overexpression of PTBP1 and TAGLN2, respectively, following miR-133b overexpression in the doxorubicin-treated HL-1 cardiomyocytes (Fig. 5A and B). In addition, overexpression of either PTBP1 or TAGLN2 rescued the miR-133b mimic-induced decreased apoptosis rate of the doxorubicin-treated HL-1 cardiomyocytes (Fig. 5C). Moreover, the increase in $\mathrm{Bcl}-2$ expression and the decrease in
Bax and cleaved caspase- 3 expression resulting from miR-133b overexpression were reversed by the overexpression of PTBP1 or TAGLN2 (Fig. 5D). Additionally, the suppressive effects of miR-133b on the protein expression levels of collagen I, III and IV, and fibronectin were abrogated by PTBP1 or TAGLN2 overexpression (Fig. 5E). All these results confirmed that overexpression of PTBP1 or TAGLN2 reversed the effects of miR-133b on apoptosis and collagen accumulation. 


\section{Discussion}

Doxorubicin is one of the most important chemotherapeutic drugs for the treatment of malignant tumors, although the cardiotoxicity of doxorubicin severely limits its clinical application (32,33). Previously, doxorubicin has been reported to induce apoptosis and impair cardiac function in heart failure $(34,35)$. In the current study, doxorubicin was used to treat HL-1 cardiomyocytes and mice to mimic cardiomyocyte injury in vitro and heart failure in vivo, respectively. The experimental results revealed that doxorubicin strongly promoted apoptosis and impaired cardiac function. Overexpression of Bax had no significant effects on the expression levels of ECM proteins, indicating that fibrotic events were independent of apoptosis.

Currently, numerous miRNAs have been shown to be dysregulated in patients with myocardial diseases and to modulate cardiomyocyte cellular processes and cardiac function $(13,25,36)$. In addition, miRNAs serve crucial roles in doxorubicin-induced myocardial diseases $(15,37,38)$. Previously, relatively lower expression levels of miR-133b have been identified in doxorubicin-treated cells and rats $(23,24,26)$. Similarly, miR-133b expression in the present study was also downregulated in the doxorubicin-treated HL-1 cardiomyocytes and mouse hearts. It has been previously demonstrated that miR-133b decreases myocardial injuries by inhibiting cardiomyocyte proliferation and the release of cytokines (31). In addition, miR-133b is involved in the regulation of cardiac fibrosis and cardioprotection of morphine preconditioning in cardiomyocytes (26). Similarly, overexpression of miR-133b in the current study inhibited apoptosis of HL-1 cardiomyocytes and suppressed collagen accumulation under doxorubicin treatment. Additionally, AAV-induced overexpression of miR-133b alleviated cardiac fibrosis in mice by decreasing collagen deposition.

Notably, miR-133b exerts its biological function by binding to the 3'-UTRs of mRNAs $(26,31)$. miR-133b improves myocardial injuries by targeting Rab27B in children with viral myocarditis (31). Moreover, miR-133b restricts cell proliferation, migration and invasion by targeting EGFR in esophageal squamous cell carcinoma (39). Hence, the present study hypothesized that miR-133b also functioned in the same way in HL-1 cardiomyocytes. After prediction and screening, PTBP1 and TAGLN2 were confirmed to serve as target mRNAs of miR-133b. miR-133b targeted the 3'-UTR of PTBP1 and TAGLN2, and decreased the protein expression levels of PTBP1 and TAGLN2, which is consistent with previous studies $(40,41)$.

PTBP1, also known as heterogeneous nuclear ribonucleoprotein 1 , belongs to a subfamily of ubiquitously expressed heterogeneous nuclear ribonucleoproteins $(42,43)$. These proteins have been reported to potentially influence pre-mRNA processing or other aspects of mRNA metabolism and transport (44). Previously, PTBP1 has been reported to induce cardiomyocyte apoptosis by enhancing caspase activity and caspase-dependent DNA fragmentation to activate apoptotic signaling (45). PTBP1 regulates pulmonary arterial hypertension by splicing pyruvate kinase muscle isoforms 1 and 2 (46). PTBP1 expression is upregulated in diabetic heart disease, and the top categories for PTBP1-regulated genes involve RNA transport, MAPK signaling and endocytosis, according to Kyoto Encyclopedia of Genes and Genomes pathway analysis (47). In addition, TAGLN2 promotes hypoxia-induced apoptosis of rat cardiomyocytes by increasing the expression levels of the apoptotic proteins caspase-8, caspase- 9 and caspase-3, and decreasing Bcl-2 expression (48). Similarly, in the present study, the rescue assays indicated that overexpression of PTBP1 or TAGLN2 reversed the effects of miR-133b on apoptosis and collagen accumulation.

In conclusion, miR-133b alleviated doxorubicin-induced cardiac fibrosis in mice by decreasing collagen deposition and suppressed apoptosis of doxorubicin-preconditioned cardiomyocytes. The protective effects of miR-133b on cardiomyocyte apoptosis and cardiac fibrosis were mediated by inhibition of PTBP1 and TAGLN2 expression. Therefore, miR-133b may be used as a biomarker to identify patients who may develop dilated cardiomyopathy after chemotherapy in the future.

\section{Acknowledgements}

Not applicable.

\section{Funding}

The present study was supported by the Nanjing Medical Science and Technology Development Special Fund (grant no. N2903-302).

\section{Availability of data and materials}

The datasets used and/or analyzed during the current study are available from the corresponding author on reasonable request.

\section{Authors' contributions}

ZL designed the experiments. ZL, JM and XG conducted the experiments. ZL, ZY, QG, JT and XG analyzed the data and made the graphs. ZL and $\mathrm{XG}$ wrote the manuscript. ZL, JM and $\mathrm{XG}$ confirmed the authenticity of all the raw data. All authors have read and approved the final manuscript.

\section{Ethics approval and consent to participate}

The animal experimental protocol was approved by the ethical committee of The First Affiliated Hospital of Nanjing Medical University (Nanjing, China; approval no. 2019-041).

\section{Patient consent for publication}

Not applicable.

\section{Competing interests}

The authors declare that they have no competing interests.

\section{References}

1. Rivankar S: An overview of doxorubicin formulations in cancer therapy. J Cancer Res Ther 10: 853-858, 2014.

2. Genovese I, Fiorillo A, Ilari A, Masciarelli S, Fazi F and Colotti G: Binding of doxorubicin to Sorcin impairs cell death and increases drug resistance in cancer cells. Cell Death Dis 8: e2950, 2017. 
3. Borlle L, Dergham A, Wund Z, Zumbo B, Southard T and Hume KR: Salinomycin decreases feline sarcoma and carcinoma cell viability when combined with doxorubicin. BMC Vet Res 15 : 36, 2019.

4. Von Hoff DD, Layard MW, Basa P, Davis HL Jr, Von Hoff AL, Rozencweig $\mathrm{M}$ and Muggia FM: Risk factors for doxorubicin-induced congestive heart failure. Ann Intern Med 91: 710-717, 1979.

5. du Pré BC, Dierickx P, Crnko S, Doevendans PA, Vos MA, Geijsen N, Neutel D, van Veen TAB and van Laake LW: Neonatal rat cardiomyocytes as an in vitro model for circadian rhythms in the heart. J Mol Cell Cardiol 112: 58-63, 2017.

6. Hole LD, Larsen TH, Fossan KO, Limé F and Schjøtt J: Diazoxide protects against doxorubicin-induced cardiotoxicity in the rat. BMC Pharmacol Toxicol 15: 28, 2014.

7. De Beer EL, Bottone AE and Voest EE: Doxorubicin and mechanical performance of cardiac trabeculae after acute and chronic treatment: A review. Eur J Pharmacol 415: 1-11, 2001.

8. Unverferth DV, Magorien RD, Leier CV and Balcerzak SP Doxorubicin cardiotoxicity. Cancer Treat Rev 9: 149-164, 1982.

9. Cecen E, Dost T, Culhaci N, Karul A, Ergur B and Birincioglu M: Protective effects of silymarin against doxorubicin-induced toxicity. Asian Pac J Cancer Prev 12: 2697-2704, 2011.

10. Burlacu A, Siriopol D, Voroneanu L, Nistor I, Hogas S, Nicolae A Nedelciuc I, Tinica G and Covic A: Atherosclerotic renal artery stenosis prevalence and correlations in acute myocardial infarction patients undergoing primary percutaneous coronary interventions: Data from Nonrandomized Single-Center Study (REN-ACS)-A single center, prospective, observational study. J Am Heart Assoc 4: e002379, 2015.

11. Lu TX and Rothenberg ME: MicroRNA. J Allergy Clin Immunol 141: 1202-1207, 2018

12. Bernardo BC, Ooi JY, Lin RC and McMullen JR: MiRNA therapeutics: A new class of drugs with potential therapeutic applications in the heart. Future Med Chem 7: 1771-1792, 2015.

13. Rupaimoole R and Slack FJ: MicroRNA therapeutics: Towards a new era for the management of cancer and other diseases. Nat Rev Drug Discov 16: 203-222, 2017.

14. Zhao L, Qi Y, Xu L, Tao X, Han X, Yin L and Peng J: MicroRNA-140-5p aggravates doxorubicin-induced cardiotoxicity by promoting myocardial oxidative stress via targeting Nrf2 and Sirt2. Redox Biol 15: 284-296, 2018.

15. Gupta SK, Garg A, Avramopoulos P, Engelhardt S, StreckfussBömeke K, Batkai S and Thum T: MiR-212/132 cluster modulation prevents Doxorubicin-Mediated atrophy and cardiotoxicity. Mol Ther 27: 17-28, 2019.

16. Li N, Zhou H and Tang Q: MiR-133: A suppressor of cardiac remodeling? Front Pharmacol 9: 903, 2018

17. Wang Y, Li M, Xu L, Liu J, Wang D, Li Q, Wang L, Li P, Chen S and Liu T: Expression of Bcl-2 and microRNAs in cardiac tissues of patients with dilated cardiomyopathy. Mol Med Rep 15: 359-365, 2017

18. Cortez-Dias N, Costa MC, Carrilho-Ferreira P, Silva D, Jorge C, Calisto C, Pessoa T, Robalo Martins S, de Sousa JC, da Silva PC, et al: Circulating miR-122-5p/miR-133b Ratio is a specific early prognostic biomarker in acute myocardial infarction. Circ J 80: 2183-2191, 2016.

19. Zhang L and Wang H: Long Non-coding RNA in CNS injuries: A new target for therapeutic intervention. Mol Ther Nucleic Acids 17: 754-766, 2019.

20. Atef MM, Amer AI, Hafez YM, Elsebaey MA, Saber SA and Abd El-Khalik SR: Long non-coding RNA EGFR-AS1 in colorectal cancer: A potential factor in tumorigenesis and survival via miRNA-133b sponge and EGFR/STAT3 axis regulation. Br J Biomed Sci 2020 (Epub ahead of print).

21. Zhao N, Liu H, Zhang A and Wang M: Expression levels and clinical significance of miR-203 and miR-133b in laryngeal carcinoma. Oncol Lett 20: 213, 2020.

22. Chen J, Li Y, Li Z and Cao L: LncRNA MST1P2/miR-133b axis affects the chemoresistance of bladder cancer to cisplatin-based therapy via Sirt1/p53 signaling. J Biochem Mol Toxicol 34: e22452, 2020.

23. Sandhu H, Cooper S, Hussain A, Mee C and Maddock H: Attenuation of Sunitinib-induced cardiotoxicity through the A3 adenosine receptor activation. Eur J Pharmacol 814: 95-105, 2017.

24. Cooper SL, Sandhu H, Hussain A, Mee C and Maddock H: Involvement of mitogen activated kinase kinase 7 intracellular signalling pathway in Sunitinib-induced cardiotoxicity. Toxicology 394: 72-83, 2018.
25. Hanousková B, Skála M, Brynychová V, Zárybnický T, Skarková V, Kazimírová P, Vernerová A, Souček P, Skálová L, Pudil R and Matoušková P: Imatinib-induced changes in the expression profile of microRNA in the plasma and heart of mice-A comparison with doxorubicin. Biomed Pharmacother 115 $108883,2019$.

26. He SF, Zhu HJ, Han ZY, Wu H, Jin SY, Irwin MG and Zhang Y: MicroRNA-133b-5p is involved in cardioprotection of morphine preconditioning in rat cardiomyocytes by targeting fas. Can J Cardiol 32: 996-1007, 2016.

27. Panizo S, Carrillo-López N, Naves-Díaz M, Solache-Berrocal G, Martínez-Arias L, Rodrigues-Díez RR, Fernández-Vázquez A, Martínez-Salgado C, Ruiz-Ortega M, Dusso A, et al: Regulation of miR-29b and miR-30c by vitamin D receptor activators contributes to attenuate uraemia-induced cardiac fibrosis. Nephrol Dial Transplant 32: 1831-1840, 2017.

28. Roca-Alonso L, Castellano L, Mills A, Dabrowska AF, Sikkel MB, Pellegrino L, Jacob J, Frampton AE, Krell J, Coombes RC, et al: Myocardial MiR-30 downregulation triggered by doxorubicin drives alterations in $\beta$-adrenergic signaling and enhances apoptosis. Cell Death Dis 6: e1754, 2015.

29. Livak KJ and Schmittgen TD: Analysis of relative gene expression data using real-time quantitative PCR and the 2(-Delta Delta C(T)) Method. Methods 25: 402-408, 2001.

30. Tao L, Bei Y, Chen P, Lei Z, Fu S, Zhang H, Xu J, Che L, Chen X, Sluijter JP, et al: Crucial role of miR-433 in regulating cardiac fibrosis. Theranostics 6: 2068-2083, 2016.

31. Zhang Y, Sun L, Sun H, Liu X, Luo X, Li C, Sun D and Li T: Overexpression of microRNA-133b reduces myocardial injuries in children with viral myocarditis by targeting Rab27B gene. Cell Mol Biol (Noisy-le-grand) 63: 80-86, 2017.

32. Balli E, Mete UO, Tuli A, Tap O and Kaya M: Effect of melatonin on the cardiotoxicity of doxorubicin. Histol Histopathol 19: 1101-1108, 2004.

33. Ganey PE, Carter LS, Mueller RA and Thurman RG: Doxorubicin toxicity in perfused rat heart. Decreased cell death at low oxygen tension. Circ Res 68: 1610-1613, 1991.

34. Saltiel E and McGuire W: Doxorubicin (adriamycin) cardiomyopathy. West J Med 139: 332-341, 1983

35. Mitani I, Jain D, Joska TM, Burtness B and Zaret BL: Doxorubicin cardiotoxicity: Prevention of congestive heart failure with serial cardiac function monitoring with equilibrium radionuclide angiocardiography in the current era. J Nucl Cardiol 10: 132-139, 2003.

36. Li J,Zhang S, Zou Y, Wu L, Pei M and Jiang Y: MiR-145 promotes miR-133b expression through c-myc and DNMT3A-mediated methylation in ovarian cancer cells. J Cell Physiol 235: 4291-4301, 2020.

37. Ruggeri C, Gioffré S, Achilli F, Colombo GI and D'Alessandra Y: Role of microRNAs in doxorubicin-induced cardiotoxicity: An overview of preclinical models and cancer patients. Heart Fail Rev 23: 109-122, 2018.

38. Lu Q, Huo J, Liu P, Bai L and Ma A: IncRNA HOXB-AS3 protects doxorubicin-induced cardiotoxicity by targeting miRNA-875-3p. Exp Ther Med 19: 1388-1392, 2020.

39. Zeng W, Zhu JF, Liu JY, Li YL, Dong X, Huang H and Shan L: MiR-133b inhibits cell proliferation, migration and invasion of esophageal squamous cell carcinoma by targeting EGFR. Biomed Pharmacother 111: 476-484, 2019.

40. Sugiyama T, Taniguchi K, Matsuhashi N, Tajirika T, Futamura M, Takai T, Akao Y and Yoshida K: MiR-133b inhibits growth of human gastric cancer cells by silencing pyruvate kinase muscle-splicer polypyrimidine tract-binding protein 1 . Cancer Sci 107: 1767-1775, 2016.

41. Zhao F, Zhou LH, Ge YZ, Ping WW, Wu X, Xu ZL, Wang M, Sha ZL and Jia RP: MicroRNA-133b suppresses bladder cancer malignancy by targeting TAGLN2-mediated cell cycle. J Cell Physiol 234: 4910-4923, 2019.

42. Coelho MB, Ascher DB, Gooding C, Lang E, Maude H, Turner D, Llorian M, Pires DE, Attig J and Smith CW: Functional interactions between polypyrimidine tract binding protein and PRI peptide ligand containing proteins. Biochem Soc Trans 44: 1058-1065, 2016.

43. Zhang H, Wang D, Li M, Plecitá-Hlavatá L, D'Alessandro A, Tauber J, Riddle S, Kumar S, Flockton A, McKeon BA, et al: Metabolic and proliferative state of vascular adventitial fibroblasts in pulmonary hypertension is regulated through a MicroRNA-124/PTBP1 (polypyrimidine tract binding protein 1)/ pyruvate kinase muscle axis. Circulation 136: 2468-2485, 2017. 
44. Pina JM, Reynaga JM, Truong AAM and Keppetipola NM Post-Translational modifications in polypyrimidine tract binding proteins PTBP1 and PTBP2. Biochemistry 57: 3873-3882, 2018.

45. Zhang J, Bahi N, Llovera M, Comella JX and Sanchis D: Polypyrimidine tract binding proteins (PTB) regulate the expression of apoptotic genes and susceptibility to caspase-dependent apoptosis in differentiating cardiomyocytes. Cell Death Differ 16: 1460-1468, 2009.

46. Caruso P, Dunmore BJ, Schlosser K, Schoors S, Dos Santos C, Perez-Iratxeta C, Lavoie JR, Zhang H, Long L, Flockton AR, et al: Identification of MicroRNA-124 as a major regulator of enhanced endothelial cell glycolysis in pulmonary arterial hypertension via PTBP1 (Polypyrimidine Tract Binding Protein) and Pyruvate Kinase M2. Circulation 136: 2451-2467, 2017.
47. Belanger K, Nutter CA, Li J, Yu P and Kuyumcu-Martinez MN: A developmentally regulated spliced variant of PTBP1 is upregulated in type 1 diabetic hearts. Biochem Biophys Res Commun 509: 384-389, 2019.

48. Li AY, Yang Q and Yang K: MiR-133a mediates the hypoxia-induced apoptosis by inhibiting TAGLN2 expression in cardiac myocytes. Mol Cell Biochem 400: 173-181, 2015.

(i) (5) This work is licensed under a Creative Commons Attribution-NonCommercial-NoDerivatives 4.0 International (CC BY-NC-ND 4.0) License. 